\title{
Agama Kristen sebagai Opium Masyarakat dan Implikasi terhadap Integrasi Nasional
}

\author{
Friska L. Piay, Donny Stevianus, Grant Nixon \\ Sekolah Tinggi Teologi Ekumene, Jakarta \\ correspondende: friskapiay@sttekumene.ac.id
}

\begin{abstract}
Indonesia as the largest archipelagic country in the world with various aspects of socio-cultural pluralism will remain a symptom that must always be taken into account in realizing national integrity and unity, a plurality or national plurality is a fact of life that has become the will of God Almighty and does not interfere with each other's faith. Religion on the one hand unites groups into groups, but on the other hand, emphasizes their differences from other groups which sometimes leads to social conflict. The quote from Karl Marx which is often misunderstood that religion is opium but through descriptive qualitative methods, the author describes religion as opium (narcotics) which relieves the pain suffered by exploited people, and about the supernatural world when all sorrow ends, suffering disappears. Christians, who are also Indonesian citizens, are called to revive the idea of nationalism both within the church (internally) and in the public (external) space with noble goals, namely, although they differ in religion, Christians view people of other religions as brothers and sisters and homeland, namely the big family of the Indonesian nation.
\end{abstract}

Keywords: Christian; Karl Marx; national integration; opium; religion

\begin{abstract}
Abstrak: Indonesia sebagai negara kepulauan terbesar didunia dengan berbagai segi kemajemukan sosialbudaya akan tetap menjadi gejala yang harus selalu diperhitungkan dalam mewujudkan keutuhan dan persatuan nasional, kemajemukan atau pluralitas bangsa adalah kenyataan hidup yang sudah menjadi kehendak Tuhan Yang Maha Kuasa dan tidak saling mengganggu keimanan masing-masing pemeluk agama. Agama di satu sisi mempersatukan kelompok ke dalam, tetapi di sisi lain mempertegas perbedaannya dari kelompok lain yang kadang-kadang berujung pada konflik social. Kutipan dari Karl Marx yang sering disalah artikan bahwa agama bersifat candu namum melalui metode kualitatif deskriptif, penulis mendeskripsikan agama ibarat opium (narkotika) yang menghilangkan rasa sakit yang diderita orang yang dieksploitasi dan mengenai dunia supranatural di masa segala kesedihan berakhir, secara penderitaan menghilang. Umat Kristen yang juga merupakan warga negara Indonesia, terpanggil untuk menghidupkan gagasan nasionalisme baik di dalam (internal) gereja maupun di ruang public (eksternal) dengan maksud tujuan yang mulia, yaitu meskipun berbeda dalam agama, umat Kristen memandang umat beragama lain sebagai saudara sebangsa dan setanah air, yakni keluarga besar bangsa Indonesia.
\end{abstract}

Kata Kunci : agama; integerasi bangsa; Karl Marx; Kristen; opium

\section{Pendahuluan}

Bangsa Indonesia diciptakan oleh Tuhan dalam suasana kemajemukan, baik dari suku, ras agama maupun budaya. Indonesia sebagai negara kepulauan terbesar didunia dengan berbagai segi kemajemukan sosial-budaya akan tetap menjadi gejala yang harus selalu diperhitungkan dalam mewujudkan keutuhan dan persatuan nasional, kemajemukan atau pluralitas bangsa adalah kenyataan hidup yang sudah menjadi kehendak Tuhan Yang Maha Kuasa dan tidak saling 
mengganggu keimanan masing-masing pemeluk agama. Pasal 29 ayat 2 UUD 1945 manyatakan bahwa negara menjamin kemerdekaan tiap-tiap penduduk untuk me-meluk agamanya masingmasing dan untuk beribadat menurut agama dan kepercayaan itu (Hamid, 2016). Agaknya tidaklah berlebihan kalau dikatakan bahwa agama itu berwajah ganda. Di satu pihak, agama telah memajukan peradaban manusia yakni menghormati kehidu-pan, menjunjung kemanusiaan universal, dan mencintai hak-hak asasi manusia. Tetapi di pihak lain, agama telah menimbulkan perpecahan, konflik, peperangan, dan pemusnahan hidup manusia. Agama di satu sisi mempersatukan kelompok ke dalam, tetapi di sisi lain memper-tegas perbedaannya dari kelompok lain yang kadang-kadang berujung pada konflik sosial (Lubis, 2013).

Sementara itu, hampir setiap agama percaya bahwa agama yang dianutnya adalah agama yang paling benar dan berusaha menyebarluaskan apa yang dipercayainya sebagai kebenaran itu. Kepercayaan seperti itu pasti akan menimbulkan konflik di tengah masyarakat yang memeluk bermacam-macam agama. Padahal kalau diamati sungguh-sungguh agama adalah juga sebuah konstruksi sosial. Hal itu berarti bahwa aspek-aspek sosial kemasyarakatan juga memengaruhi kehidupan beragama (Lubis, 2013). Beberapa tahun terakhir Indonesia mengalami gejolak dalam hal politisasi agama dimana agama tertentu dijadikan alat untuk mempertahankan suatu kekuasaan yang mengakibatkan pertentangan antar kelompok dan golongan ditengah masyarakat. Agama dalam kaitannya dengan masyarakat dapat merupakan daya penyatu (sentripetal) dan bisa menjadi daya pemecah (sentrifugal) (Sudioyono, Lue \& Palupi, 2016).

Di tengah derasnya arus gerakan keagamaan yang berwatak fundamentalis radikal di Indonesia, baik dalam dunia maya dan dunia nyata yang diaktualisasi dengan diskriminasi, intoleransi maupun terorisme. Umat Kristen yang juga merupakan warga negara Indonesia, terpanggil untuk menghidupkan gagasan nasionalisme baik di dalam (internal) gereja maupun di ruang public (eksternal) dengan maksud tujuan yang mulia, yaitu meskipun berbeda dalam agama, umat Kristen memandang umat beragama lain sebagai saudara sebangsa dan setanah air, yakni keluarga besar bangsa Indonesia (Triposa \& Alex, 2021). Alkitab sebagai landasan dalam membangun manusia untuk dididik dan dibimbing sebagai manusia yang taat pada kebenaran, agar berperilaku sesuai dengan norma-norma ajaran Kristen. Juga diwajibkan tun-duk terhadap sistem pemerintahan yang secara norma dan hukum tidak melanggar kemanu-siaan. Sebab sejatinya nilai-nilai Pancasila tidak bertentangan dengan ajaran agama Kristen (Triposa \& Alex, 2021).

Agama adalah candu atau aslinya ditulis dalam Bahasa Jerman, Die Religion ... ist das Opium des Volkes (terjemahan langsung: "Agama... adalah opium bagi masyarakat"), adalah kutipan terkenal sekaligus sepotong-sepotong dari tulisan Karl Marx. Pernyataan ini, sering diartikan bahwa Karl Marx menuduh agama itu menyesatkan dan menipu masyarakat. Selain itu, pernyataannya ini juga dipakai dalam arti tuduhan bahwa agama dengan menjanjikan kebahagiaan di alam sesudah kehidupan, membuat orang tertindas atau miskin menerima nasib mereka tanpa ada tindakan untuk mengubah keadaan tersebut (Munir, 2016). Agama ibarat opium (narkotika) yang menghilangkan rasa sakit yang diderita orang yang dieksploitasi dan mengenai dunia supranatural di masa segala kesedihan berakhir, secara penderitaan menghilang. Agama bukan pelarian, agama justru memberdayakan para penganutnya untuk membangun masyarakat yang solider dengan mereka yang miskin dan lemah, masyarakat yang positif, damai saling menghormati serta melawan ketidakadilan dan penindasan mereka yang tidak berdaya. Otomatis, profil para agamawan harus memperlihatkan bahwa mencari Tuhan-nya bukan hanya 
tidak mengasingkan manusia dari dirinya sendiri, melainkan justru akan mengembangkan identitas dan hakekatnya yang positif (Munir, 2016).

Opium adalah golongan obat untuk mengendalikan rasa sakit, efek opioid dapat membuat beberapa orang merasa rileks dan bahagia (Rahardjo et al., 2020). Jelas bahwa Karl Marx justru menganggap agama sebagai opium yang maksudnya sarana meringankan beban bagi manusia, alih-alih menuduhnya sebagai sebagai candu yang menyebabkan ketergantungan. Konteks opium adalah sebagai obat peringan beban pikiran. Tujuan penulisan artikel ini adalah untuk mengetahui apa saja peran Agama Kristen jika di pandang sebagai opium bagi masyarakat dalam menjaga integerasi nasional.

\section{Metode Penelitian}

Penelitian ini menggunakan metode kualitatif deskriptif (Arifianto \& Purnama, 2020). Penulis menggunakan sumber-sumber literatur yang memiliki korelasi dengan masalah penelitian. Sumber-sumber yang dipakai berupa buku fiksi, e-book, dan jurnal. Tahap pertama penulis menjelaskan konsep agama Kristen, definisi serta fungsi zat Opium sebagai penenang dan pereda "rasa sakit" dihubungan dengan peran agama Kristen sebagai opium ditengah masyarakat dalam menjaga integerasi Nasional.

\section{Pembahasan}

Para ilmuan sosial mendefinisikan agama berdasarkan substansinya (definisi substantif), berdasarkan fungsinya (definisi fungsional), dan berdasarkan deskripsi ciri-ciri yang sama dalam agama (definisi deskriptif). Edward Tylor mendefinisikan agama sebagai "kepercayaan terhadap wujud-wujud spiritual" Emile Durkheim mendefinisikan Agama adalah suatu sistem terpadu dari kepercayaan-kepercayaan dan ibadat-ibadat yang berkaitan dengan benda-benda sakral, kepercayaan-kepercayaan dan ibadat-ibadat yang mempersatukan semua orang yang menganut kepercayaan-kepercayaan itu ke dalam satu komunitas moral yang disebut Gereja. Y. Yinger mengartikan agama sebagai sistem kepercayaan dan peribadatan yang berfungsi untuk mengatasi persoalan-persoalan di dalam hidup

Clifford Geertz mengartikan agama sebagai sistem simbol yang berfungsi untuk menentramkan suasana hati dan memberikan motivasi yang kuat dan tahan lama di dalam kehidupan manusia dengan menetapkan konsep-konsep atau merumuskan kepercayaan-kepercayaan tentang tatanan umum eksistensi (manusia dan masyarakat) dan 'membungkus' konsep-konsep atau kepercayaan itu seolah-olah sebagai sesuatu yang riil atau merupakan fakta sehingga sua-sana batin dan motivasi yang terciptapun menjadi riil. Elisabeth Nothingham agama berkaitan dengan dengan usaha-usaha manusia untuk mengukur kedalaman makna dari keberadaannya sendiri dan keberadaan alam semesta. Agama telah menimbulkan kayalan yang paling luas dan juga digunakan untuk membenarkan kekejaman yang luar biasa terhadap orang lain (Lubis, 2013). Secara umum, agama dapat didefisinikan sebagai sistem yang mengatur kepercayaan dan peribadatan Kepada Tuhan serta tata kaidah yang berhubungan dengan buda-ya, serta pandangan dunia yang menghubungkan manusia dengan tatan kehidupan (Prinada, 2021).

\section{Agama Kristen di Indonesia}

Agama Kristen adalah sebuah kepercayaan yang berdasar pada ajaran, hidup, sengsara, wafat dan kebangkitan Yesus Kristus atau Isa Almasih. Agama ini meyakini Yesus Kristus adalah Tuhan dan Mesias, juru selamat bagi seluruh umat manusia, yang menebus manusia dari dosa. Mereka beribadah di gereja dan Kitab Suci mereka adalah Alkitab. Murid-murid Yesus Kristus pertama kali dipanggil Kristen di Antiokia (Kis. 11:26) (ARDIATO, 2010). 
Agama Kristen adalah agama terbesar kedua di Indonesia. Agama Kristen ini masuk ke Indonesia sekitar abad ke-9. Perkembangan agama Kristen di Indonesia bisa digolongkan jadi dua bagian, yaitu Kristen Katolik dan Kristen Protestan. Penyebaran agama Kristen dilakukan melalui pelayaran dan perdagangan. Berdasarkan Website Portal Informasi Indonesia, ada enam agama yang diakui keberadaannya di NKRI yaitu Islam, Protestan, Katolik, Hindu, Budha dan Konghucu (Indonesia, 2021). Mayoritas umat Kristen Indonesia adalah umat Protestan. Dari 23,5 juta total penduduk Indonesia beragama Kristen, sekitar 16,5 juta orang mengikuti ajaran-ajaran Protestan, sementara 7 juta orang lainnya mengikuti ajaran-ajaran Katolik (Invest-men, 2021).

Agama Kristen adalah agama terbesar kedua di Indonesia. Perkembangan agama Kristen di Indonesia digolongkan jadi dua bagian, yaitu Kristen Katolik dan Kristen Protestan. Penyebaran agama Kristen dilakukan melalui pelayaran dan perdagangan. Proses masuknya agama Kristen ke Indonesia terjadi dalam dua waktu. Pertama agama Kristen masuk di Indonesia sejak zaman kuno. Menurut Cosmas Indicopleustes dalam bukunya Topographica Christiana, pada abad ke6 sudah ada komunitas Kristiani di India Selatan, di pantai Malabar, dan Sri Lanka. Dari Malabar itu agama Kristen menyebar ke banyak daerah. Di tahun 650 agama Kristen mulai berkembang di Kedah atau Semenanjung Malaya dan sekitarnya. (Ratna, 2016). Di abad ke-9, daerah Kedah berkembang menjadi pelabuhan dagang yang sangat ramai di jalur pelayaran yang menghubungkan jalur dari India ke Aceh ke Barus ke Nias dan melalui Selat Sunda-Laut Jawa dan terus ke Cina. Jalur inilah yang sering disebut sebagai jalur penyebaran agama Kristen dari India ke Nusantara.

\section{Agama Sebagai Opium}

Karl Marx seorang sosiolog sekaligus sejarahwan pernah menggemparkan dunia dengan pernyataannya bahwa "agama adalah opium bagi masyarakat". Karl Marx lahir di kota kecil Rhineland, Thrier Jerman tanggal 5 Mei 1818 dan wafat 1883. Ia merupakan anak kedua dari delapan bersaudara. Ayahnya, Heinrich, seorang pengacara Yahudi, dan kakeknya seorang Rabbi Yahudi. Kepribadian Marx sangat berbeda dengan ayahnya, dia anak yang keras kepala, kasar, agak liar dan jarang mengedepankan perasaannya, tetapi ia memiliki bakat intelektual. Selain ia bersekolah secara formal, ia mendapatkan tambahan pendidikan dari Baron von Westphalen yang akhirnya berkontribusi dalam menumbuhkan minatnya terhadap sastra klasik (Lutfi, 2019). Ketika mengaitkan antara agama dengan Marx, hampir semua orang berasumsi Marx adalah musuh agama atau orang yang beragama. Faham sosialisme dan komunisme selalu dialamatkan pada dirinya. Apa yang dilakukan oleh pengikut, pengkritik dan penafsir pandangan-pandangannya tentang agama cenderung melihat pada sisi bahwa ia menolak mentah-mentah apa yang disebut Tuhan atau agama.

Pandangan Marx terhadap agama tidak bisa dilepaskan dari pengalaman dan sejarah hidupnya dan juga keluarganya. Pada usia Marx masih kecil, keluarganya hampir bisa dikatakan dipaksa untuk berpindah agama dari sebelumnya Yahudi ke Kristen. Alasan pindah agama keluarga Marx dikarenakan ayahnya yang ingin menjadi Pegawai Negeri sebagai Notaris. Kebijakan negara pada saat itu tidak memperkenankan pegawainya beragama selain agama penguasa. Kejadian pindah agama ini, bagi Marx sangat membekas dan membuatkan miris yang akhirnya ia mengambil kesimpulan bahwa agama tidak lebih dari tong sampah tempat lalat mengais sisa-sisa makanan. Begitu rendahnya agama yang dapat ditukar dengan materi. Negara sangat berkuasa untuk menentukan agama warganya dengan iming-iming ma-teri (Lutfi, 2019).

Selain pengalaman keberagamaan individu dan keluarga yank?)g ia alami, secara eksternal Marx dihadapkan kepada kondisi sosial keagamaan yang menurutnya sangat menginjak-injak 
martabat manusia yang dipelopori oleh negara yang dimotori oleh kaum bangsawan dan kapitalis dengan mengeruk kekayaan di atas penderitaan masyarakat bawah, sementara para agamawan tinggi Protestan tidak lagi memperlihatkan fungsi profetiknya, bahkan yang terjadi mereka melegitimasi putusan politik penguasa dengan memberikan nasihat agama agar menerima kondisi dan kenyataan hidup yang mereka hadapi. Nilai-nilai agama yang dibuat candu bagi masyarakat miskin agar mereka menerima kondisi yang mereka hadapi, sementara para penguasa tetap pada posisi kekuasaannya dan mempertahankan status quo.

Sampai dengan uraian di atas, sangat tampak apa yang dikritik oleh Marx sebenarnya bukanlah agama, tetapi umat yang memeluk agama. Agama dijadikan layaknya komoditas, tidak ada bedanaya dengan politik, ekonomi dan sosial. Sebenarnya apa yang dikritik oleh Marx tentang agama merupakan kritik antara saja, sasaran yang ingin ia capai adalah melalui kritiknya terhadap agama, ia ingin melakukan kritik kepada masyarakat. Oleh karena kondisi sosial dan lingkungannya tidak lagi bersahabat dan mengasingkan dirinya, maka manusia membangun dunia atau singgasana lain di dalam khayalan yang dianggap mampu menampung segala keluhan yang di hadapinya. Kemudian ia mengharapkan suatu kedamaian dan keselamatan di langit atau surga. Dari sini ia mendapatkan agama berfungsi seperti opium yang memberikan kedamaian dan kebahagiaan (Lutfi, 2019).

Opium adalah golongan obat untuk mengendalikan rasa sakit, efek opioid dapat membuat beberapa orang merasa rileks dan bahagia. Obat analgesik, terutama opioid (opium), telah menjadi fokus utama penelitian medis karena peran penting mereka dalam menghilangan rasa sakit (Rahardjo et al., 2020). Namun, penggunaan opium secara tidak wajar dapat menye-babkan kecanduan, dan dapat merusak kesehatan bila digunakan berlebihan dan berefek ketergantungan. Demikian halnya Agama harusnya memberi ketenangan namun jika digunakan oleh orang yang tidak bertanggung jawab maka akan menyebabkan orang lebih mencintai agama daripada pada Tuhan dan berujung pada radikalisme agama.

\section{Integrasi Nasional}

Integrasi Nasional berasal dari bahasa Inggris yaitu Integration yang berarti persatuan atau penggabungan dan Nasional dari kata Nation yang berarti bangsa, jika digabungkan maka integrasi nasional adalah usaha dan sebuah proses dalam mempersatukan banyak perbedaan dari masyarakat kecil menjadi satu keseluruhan yang lebih utuh dalam sebuah Negara, sehingga tercipta keselarasan secara menyeluruh (Suparyanto, 2021). Dalam suatu Negara, integrasi nasional adalah suatu hal yang diperlukan untuk dapat mengejawantahkan sinergi maksimal dari kesatuan rakyat, yaitu wilayah dan pemerintahnya (Bahar, 2018).

Myron Weiner memberikan lima definisi tentang integrasi, yaitu:

1. Membangun rasa kesatuan dan mengesampingkan ikatan yang menjadi sekat, sehingga antara budaya dan sosial yang berbeda dapat Bersatu.

2. Integrasi lebih merujuk pada pembentukan wewenang kekuasaan pusat dibanding divisi-divisi yang lebih kecil.

3. Integrasi merupakan cara mendekatkan banyak perbedaan aspirasi pada kelompok elit dan masa.

4. Integrasi merupakan kesepakatan dalam memegang nilai-nilai fundamental yang diperlukan dalam memelihara kesatuan.

5. Integrasi merupakan pembentukan tingkah laku antar individu yang dapat diterima demi sebuah tujuan bersama (Nurdiansyah \& Dhita, 2020). 
Integrasi nasional adalah usaha dan proses mempersatukan perbedaan yang ada pada suatu negara sehingga terciptanya keserasian dan keselarasan secara nasional. Seperti yang kita ketahui, Indonesia merupakan bangsa yang sangat besar baik dari kebudayaan ataupun wilayahnya. Di satu sisi hal ini membawa dampak positif bagi bangsa karena kita bisa

memanfaatkan kekayaan alam Indonesia secara bijak atau mengelola budaya budaya yang melimpah untuk kesejahteraan rakyat, namun selain menimbulkan sebuah keuntungan, hal ini juga akhirnya menimbulkan masalah yang baru. Kita ketahui dengan wilayah dan budaya yang melimpah itu akan menghasilkan karakter atau manusia manusia yang berbeda pula sehingga dapat mengancam keutuhan bangsa Indonesia (Astawa, 2017).

\section{Peran Agama Kristen}

Sebagai Umat Kristen yang berarti pengikut Kristen berdasarkan Kolose 3:12-14, "Karena itu, sebagai orang-orang pilihan Allah yang dikuduskan dan dikasihi-Nya, kenakanlahbelas kasihan, kemurahan, kerendahan hati, kelemahlembutan dan kesabaran. Sabarlah kamu seorang terhadap yang lain, dan ampunilah seorang akan yang lain apabila yang seorang menaruh dendam terhadap yang lain, sama seperti Tuhan telah mengampuni kamu, kamu perbuat jugalah demikian. Dan di atas semuanya itu: kenakanlah kasih, sebagai pengikat yang mempersatukan dan menyempurnakan.

Setiap Orang Kristen harus memelihara kasih yang mempersatukan. Ciri yang Pertama dari Kasih yang Mempersatukan menurut Kol. 3:12-14 adalah hidup yang rendah hati. Hidup yang Rendah Hati meliputi kerendahan hati dan saling mengampuni. Ketika seseorang mau mengampuni itu menunjukkan kerendahan hati, di mana ia mau menerima kekurangan oang lain. Kerendahan hati berarti juga kita mau mengalah, sehingga terjadi kerukunan. Perbedaan pendapat, kesalahan tidak dapat dihindari dalam kehidupan berbangsa dan bernegara namun hal yang lebih jauh, yaitu perkelahian dapat kita hindari ketika kita mau merendahkan diri, mau memaafkan, mau mengampuni orang yang bersalah pada kita.

Kemampuan kita merendahkan diri, dan mengampuni orang lain tergantung dari sejauh mana kita menyadari anugerah, kasih pengampunan yang diberikan Allah dalam Yesus Kristus pada kita. Sejauh mana kita menyadari dosa-dosa kita yang sangat besar itu diampuni Allah dengan kematian-Nya di kayu salib? (ay.14). Sejauh itu juga kita dapat mengampuni orang lain. Pengampunan dapat terjadi walau seseorang tidak minta ampun atas kesalahannya kepada kita, dan itulah Kasih Allah itu, yaitu anugerah itu. Kerendahan Hati dan mau mengampuni, adalah sejata yang sangat ampuh mempertahankan kesatuan atau kerukunan

Selain itu juga hidup yang sabar. Hidup yang sabar meliputi Kelemah lembutan dan kesabaran. Kedua gaya hidup ini sangat berperan dalam menghidari terjadinya perkelahian atau perpecahan dalam satu komunitas atau gereja. Sabar dalam mendengar orang berbicara, dan sabar dalam memberi jawaban; sabar dalam mengambil keputusan; kemudian lemah-lembut dalam bertanya atau memberi jawaban, adalah salah satu senjata dalam menciptakan dan mempertahankan kesatuan atau kerukunan.

Berikutnya, hidup yang mau berbagi. Hidup dalam belas kasihan dan kemurahan, kami satukan menjadi hidup yang mau berbagi, atau hidup yang mau menolong. Salah satu Kunci yang sangat jitu menghadirkan kesatuan atau kerukuan adalah kalau terjadi saling berbagi, saling tolong menolong diantara komunitas atau diantara berbangsa dan bernegara. Ketika seseorang mengalami kesulitan, dan ia mendapat pertolongan, adalah sangat menyejukkan. Hal inilah yang diinginkan Allah, seperti Firman Tuhan dalam Galatia 6:2, Bertolong-tolongan-lah kamu menanggung bebanmu, demikianlah kamu memenuhi hukum Kristus." Pertolongan yang 
diterima oleh orang yang membutuhkan adalah seperti kesejukan embun gunung Her-mon, yang dirasakan gunung gunung lainnya yang tandus di Sion. Gunung Hermon mau berbagi kesejukannya kepada gunung yang lain.

\section{KESIMPULAN}

Di tengah derasnya arus gerakan keagamaan yang berwatak fundamentalis radikal di Indonesia, baik dalam dunia maya dan dunia nyata yang diaktualisasi dengan diskriminasi, intoleransi maupun terorisme. Umat Kristen yang juga merupakan warga negara Indonesia, terpanggil untuk menghidupkan gagasan nasionalisme baik di dalam (internal) gereja maupun di ruang public (eksternal) dengan maksud tujuan yang mulia, yaitu meskipun berbeda dalam agama, umat Kristen memandang umat beragama lain sebagai saudara sebangsa dan setanah air, yakni keluarga besar bangsa Indonesia. Layaknya Opium yang dapat memberikan kelepa-san dari rasa sakit dan memberi kebahagiaan, Agama Kristen yang diterapkan oleh pengikut Kristus yang sejati diharapkan menjadi penenang ditengah masyarakat Indonesia.

\section{REFERENSI}

ARDIATO, R. (2010). LANDASAN KONSEPTUAL PERENCANAAN DAN PERANCANGAN GEREJA BETHEL INDONESIA KELUARGA ALLAH YOGYAKARTA [UNIVERSITAS ATMA JAYA YOGYAKARTA]. http://e-journal.uajy.ac.id/3317/

Arifianto, Y. A., \& Purnama, F. (2020). Misiologi dalam Kisah Para Rasul 13 : 47 Sebagai Motivasi Penginjilan Masa Kini. Kharisma: Jurnal Ilmiah Teologi, 1(2), 117-134. http://jurnalsttkharisma.ac.id/index.php/Kharis/article/view/39

Astawa, P. A. (2017). Integrasi Nasional. Universitas Udayana, 1-25.

Bahar, S. (2018). Etnik, Elite dan Integrasi Nasional. Gre Publisher.

Hamid, A. (2016). DINAMIKA INTEGRASI NASIONAL BANGSA INDONESIA (Dalam Pendekatan Kerukunan Umat Beragama). Istiqra, 4(2), 319. https://doi.org/10.24239/istq.v4i2.211.319-340

Indonesia, P. I. (2021). Profil Agama Indonesia. Indonsia.Go.Id. https://indonesia.go.id/profil/agama

Investmen, I. (2021). Agama Kristen \& Katolik di Indonesia. Indonesia Investmen. https://www.indonesia-investments.com/id/budaya/agama/kristen-katolik/item249

Lubis, R. (2013). Sosiologi Agama. In Sosiologi agama (Vol. 53, Issue 9).

Lutfi, A. (2019). Agama Sebagai Tempat Pelarian Diri (?) (Suatu Tinjauan Sosiologi Agama Perspektif Karl Marx). Jurnal Ilmu Dakwah \& Pembangunan, XIV, 1-16.

Munir, M. (2016). PEMIKIRAN KARL MARX TENTANG AGAMA. Citra Ilmu, xii, 155-163. https://d1 wqtxts1xzle7.cloudfront.net/61473765/citra_ilmu_edisi_24_vol_xii_Oktober_2 016_220191210-116529-681cyl-with-cover-pagev2.pdf?Expires $=1637858428 \&$ Signature=DjtjK9Zh1S7vo2sfNRQZocoj1VsN7mPRkZmgIL3JIQo573RcYITorYwGDz dwDCBewvqwOKUOjYlgo2xShKj8F1R-

Nurdiansyah, E., \& Dhita, A. N. (2020). Perwujudan Integrasi Nasional Pada Masyarakat Kota Palembang. Jurnal Pendidikan Kewarganegaraan, 10(1), 29. https://doi.org/10.20527/kewarganegaraan.v10i1.7165

Prinada, Y. (2021). Apa Itu Agama Menurut Para Ahli: Sejarah, Macam, \& Perkembangan. Tirto.Id. https://tirto.id/apa-itu-agama-menurut-para-ahli-sejarah-macam-perkembangangaHK

Rahardjo, S., Widyastuti, Y., \& Rumpok, T. M. (2020). Efek Imunologi Pada Penggunaan Opioid Akut Dan Kronis. Jurnal Komplikasi Anestesi, 7(3), 83-95. http://anestesi.fk.ugm.ac.id/jka.ugm/download-file-706825.pdf

Ratna, D. (2016). Belajar sejarah perkembangan agama Kristen di Indonesia, yuk! Merdeka.Com. https://www.merdeka.com/pendidikan/belajar-sejarah-perkembangan- 
agama-kristen-di-indonesia-yuk.html

Sudioyono, Lue \& Palupi, Y. (2016). Ilmu Sosial Dasar (Pertama). Kaliwangi Offset.

Suparyanto. (2021). Pendidikan Kewarganegaraan. Qiara Media.

Triposa, R., \& Alex, Y. (2021). Strategi Guru PAK Dalam Membangun Pancasila sebagai Paradigma Integerasi Bangsa terhadap Peserta Didik di Era Milenial. Teologi Berita Hidup, 4, 165-179. 